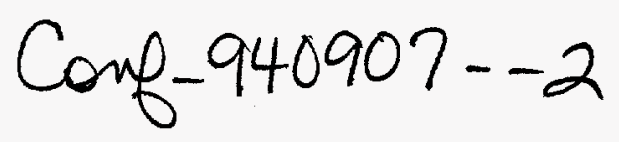

\title{
LABORATORY INVESTIGATION OF CONSTITUTIVE PROPERTY SCALING BEHAVIOR
}

\author{
Vincent C. Tidwell, Sandia National Laboratories
}

\begin{abstract}
Property scaling becomes an issue whenever heterogeneous media properties are measured at one scale but applied at another (i.e., data is collected at the core scale but analysis is conducted at the grid block scale). A research program has been established to challenge current understanding of property scaling with the aim of developing and testing models that describe scaling behavior in a quantitative manner. Scaling of constitutive rock properties is investigated through physical experimentation involving the collection of gas-permeability data measured over a range of discrete scales. The approach is to systematically isolate those factors that influence property scaling and investigate their relative contributions to overall scaling behavior. Two blocks of rock, each exhibiting differing heterogeneity structure, have recently been examined. The two samples were found to yield different scaling behavior, as exhibited by changes in the distribution functions and semivariograms. Simple models have been fit to the measured scaling behavior that are of similar functional form but of differentmagnitude.
\end{abstract}

\section{Introduction}

Numerical simulation aimed at evaluating the production characteristics of an economic reservoir require detailed information on the geology and material properties of the reservoir. The acquisition of such information through reservoir characterization is complicated by the fact that many of the important hydraulic, chemical, thermal and mechanical properties are measured at scales (as limited by current technology) much smaller than can be accommodated in current reservoir simulators (as limited by computation time). In many cases the discrepancy between the measurement and analysis scales is many orders of magnitude on a per volume basis $\left(\mathrm{cm}^{3}\right.$ to $\left.\mathrm{km}^{3}\right)$. It is well established that many properties, particularly constitutive properties, are scale dependent. ${ }^{1-4}$ That is, as the scale of measurement is increased, changes in the distribution function and semi-variogram are realized. For this reason scaling models are required for transforming information (i.e., distribution function and semi-variogram, which represent the key input to 1-, 2-, and 3-D reservoir property models) from the scale of the available data to the scale at which simulations will ultimately be performed. This raises such questions as:
- do rock properties scale in a predictable and quantifiable manner;
- if so, what is the nature of the scaling behavior;
- how does property heterogeneity influence scaling behavior; and
- how should the characterization of scaling behavior be approached?

A number of theories, representing a wide diversity of approaches, have been proposed for "scaling-up" measurements; 5 12 however, physical data to support these theoretical models are sparse and limited in scope. ${ }^{13-15}$ For this reason, a research program founded on systematic physical experimentation has been established to challenge current understanding of propertyscaling behavior. ${ }^{16}$ The experimental program involves the collection of gas permeability data at a number of discrete measurement scales, thereby providing a direct means of investigating scaling behavior. Factors influencing scaling behavior (i.e., heterogeneity structure, characteristics of the sampling and analysis program) are varied in a systematic fashion to isolate relative contributions to overall scaling behavior. The data are used to explore potential empirical scaling relationships and directly challenge existing scaling theory. 


\section{DISCLAIMER}

This report was prepared as an account of work sponsored by an agency of the United States Government. Neither the United States Government nor any agency thereof, nor any of their employees, make any warranty, express or implied, or assumes any legal liability or responsibility for the accuracy, completeness, or usefulness of any information, apparatus, product, or process disclosed, or represents that its use would not infringe privately owned rights. Reference herein to any specific commercial product, process, or service by trade name, trademark, manufacturer, or otherwise does not necessarily constitute or imply its endorsement, recommendation, or favoring by the United States Government or any agency thereof. The views and opinions of authors expressed herein do not necessarily state or reflect those of the United States Government or any agency thereof. 


\section{DISCLAIMER}

Portions of this document may be illegible in electronic image products. Images are produced from the best available original document. 
The purpose of this paper is to present the results of recent scaling experiments conducted on two rock samples exhibiting differing heterogencity characteristics. The paper begins with a description of the approach and laboratory method being used to physically measure and quantify scaling behavior. Attention is then turned to describing the rock samples used in this investigation. Results of the investigation are then discussed, followed by concluding remarks and plans for future work.

\section{Physical Investigation of Scaling Behavior}

Physical investigation of property-scaling behavior requires the collection of large suites of data measured over a range of discrete scales. Measurements must be made in a similar manner regardless of scale, with consistent physical boundaries and geometry and with a high level of precision. For purposes of this investigation, measurements also need to be rapid, inexpensive, and non-destructive. An instrument meeting these criteria and employed in this investigation is the gas permeameter.

The gas permeameter was originally developed in the petroleum industry for rapid field and laboratory acquisition of gaspermeability data. Since that time, the gas permeameter has found widespread use in the characterization of sandstones, ${ }^{17,18}$ welded tuffs, ${ }^{19}$ and carbonates. ${ }^{20}$ Measurements are made by compressing the permeameter tip-seal against a rock surface and injecting gas into the rock while measuring the flow rate and gas pressure (from which the gas permeability can be calculated). Of the three basic permeameter designs that exist, ${ }^{21-23}$ a system based on steady gas flow and constant injection pressure was adopted for this program. The permeameter consists of four mass-flow meters $\left(0-50,0-500,0-2000\right.$, and $0-20,000 \mathrm{~cm}^{3} / \mathrm{min}$ [at standard conditions]), a pressure transducer $(0-100 \mathrm{KPa}$ gauge), a barometer, and temperature sensor that are connected to a regulated source of compressed nitrogen (Figure 1a). A series of specially designed tip seals, the diameter of which defines the scale of measurement, are used to establish a known boundary condition on the rock surface (Figure 1b). Thus, by changing the size of the tip seal, the permeameter interrogates volumes of rock ranging in scale from tenths to thousands of cubic centimeters. A soft, durable silicone rubber is used to establish the seal between the injection nozzle and the rock surface.

To improve measurement precision and facilitate data collection, the gas permeameter has been automated for laboratory use. ${ }^{24}$ Operation of the electronic permeameter instruments and solenoids (electronic valves) are controlled by specially adapted PC-based software. An x-y positioning system coupled with a pneumatic piston has also been automated for positioning and compressing the permeameter-tip seal against the rock surface (Figure 1c). This system allows more than 300 measurements to be made in an eight hour period, unattended.

Gas permeability is calculated directly from information on seal geometry, flow rate, and injection pressure. These calculations are accomplished by means of a modified form of Darcy's Law as developed by Goggin, ${ }^{25}$

$$
k=\frac{Q_{1} \cdot P_{1} \cdot \mu}{a \cdot G_{0} \cdot 0.5 \cdot\left(P_{1}{ }^{2}-P_{0}{ }^{2}\right)}
$$

where $k$ is gas permeability, $Q_{1}$ is gas-flow rate, $P_{0}$ is atmospheric pressure, $P_{I}$ is gas injection pressure, $\mu$ is gas viscosity, $a$ is internal tip-seal radius, and $G_{O}$ is a geometric factor. In this model all of the complexities associated with the flow-field geometry are summarized into a single, empirically derived, dimensionless quantity, $\mathrm{G}_{o}$, which is a function only of tip seal size. For measurements in a semi-infinite half-space (outcrop or large block measurements); the resulting gas-flow field is hemispherical. Based on numerical experimentation Goggin ${ }^{25}$ concluded that the effective radius of the hemispherical gas-flow field is approximately four times the inner tip-seal radius. This implies that the effective volume, $V$, of rock interrogated by the permeameter is,

$$
\mathrm{V}=0.66 \cdot \pi \cdot\left(64 \cdot \mathrm{a}^{3}\right)
$$

Tip seal sizes employed in this study have inner radii of 0.15 , $0.31,0.63,1.27$, and $2.54 \mathrm{~cm}$, and an outer radii measuring twice the inner. The corresponding volume of rock interrogated by the different tip seals is $0.5,4.3,34,275$, and $2200 \mathrm{~cm}^{3}$, respectively.

Large boulders of rock, capable of yielding blocks measuring $0.6-1.3 \mathrm{~m}$ on a side, are acquired for gas permeameter testing. Shaping of boulders into blocks is necessary to provide a fresh, flat surface for making measurements. Blocks are preferred over slabs because, for the tip-seals used in this study, blocks provide a sampling domain that is thick relative to the penetration of the permeameter measurement. Also, the three-dimensionality of the block allows samples with anisotropic heterogeneity structure to be interrogated in three orthogonal orientations. Rock samples are cut using a diamond-impregnated wire line saw. Fresh water is used to lubricate and cool the wire line during cutting as well as to pressure wash the sawn surfaces (to remove cuttings from open rock pores). Orthogonal faces are cut from the boulders along the inferred (from visual inspection) principal permeability axes.

Investigating the Influence of Sample Heterogeneity on Scaling Behavior

Systematic experimentation is employed to investigate those factors that influence scaling behavior. Of particular interest to this investigation is the effect of sample heterogeneity on scaling behavior. Here, heterogeneity is defined as the sum total of the attributes of a rock that define its basic fabric; more specifically, those attributes that govern contrast in the gas permeability field. Another factor that influences scaling behavior is the relative scale of the heterogeneity to that of the measurement. The basic approach taken to investigate the influence of such factors relies on the careful selection of rock samples for analysis. Samples are collected that exhibit differing heterogeneity structure at differing scales. Gas permeability measurements are then collected from the different samples and the measured scaling 
behavior (as exhibited by changes in the distribution functions and semi-variograms) is compared.

Two rock samples have recently been collected for investigation. Both samples were collected from the crest of Yucca Mountain, NV, located approximately $160 \mathrm{~km}$ northwest of Las Vegas. Yucca Mountain is currently under investigation as a potential site for the nation's first high-level radioactive waste repository. The samples are associated with the Tiva Canyon Member of the Paintbrush Tuff, Upper Cliff (called Tiva Cliff) microstratigraphic unit and Caprock (called Tiva Cap) microstratigraphic unit, respectively. ${ }^{26}$ The Tiva Cliff sample ( 1.3 by 1.3 by $0.6 \mathrm{~m}$ block) is a welded tuff that has undergone vapor phase alteration. The sample exhibits a clastic fabric; lithic and pumice fragments bound by a fine grain groundmass. The lithics and pumice are subround to angular. In contrast to the lithics, the pumice fragments are distinctly flattened resulting in a "pancake" appearance. The Tiva Cap sample ( 1.2 by 0.6 by $0.4 \mathrm{~m}$ block) is a poorly welded tuff which exhibits an aphanitic fabric with very small, subround pumice fragments.

To evaluate the effect of heterogeneity on scaling behavior, an independent measure of the size and shape of the heterogeneity structure of the sample is needed. In both samples used in this study, it is the high-porosity pumice grains that give rise to contrast in the measured gas permeability field. High resolution images of each rock face were acquired using a digital, chargedcoupled device (CCD) camera. Analysis of the acquired images yield the size and shape of each pumice grain. The frequency distribution of pumice grain size (length of the major grain axis) is given for each sample (Figure 2). In both samples frequency is noted to decrease exponentially with size, with the sharpest decay occurring in the Tiva Cap sample. It is important to note that pumice present in the Tiva Cap sample is generally smaller than all but the smallest tip seal while this is not the case for the Tiva Cliff sample.

\section{Results of Multi-Scale Measurements}

Gas permeability measurements were made on a single face of both the Tiva Cliff and Tiva Cap samples. Measurements on the Tiva Cliff sample were collected from the face cut normal to the direction of pumice flattening. Data were collected on a square grid ( 30 by 30 ) with $2.54 \mathrm{~cm}$ centers using each of the five tip seals. Measurements on the Tiva Cap sample were also collected on a grid (10 by 37 ) with $2.54 \mathrm{~cm}$ centers. Again, all five tip seals were used. It should be noted that for the $0.63,1.27$, and $2.54 \mathrm{~cm}$ tip-seals overlap between neighboring measurements occurs (see Equation 2). The acquired data have been reduced via Equation 1 and reported in terms of gas permeability $\left(\mathrm{m}^{2}\right)$. Precision of the gas permeameter has been established elsewhere and hence will not be discussed here. ${ }^{16,24}$

The distribution functions measured with each of the five tip seals on the Tiva Cliff sample are shown in Figure 3. Each of the five distributions are unimodal and non-normal (skewed). The mean, variance, and skewness of each distribution are seen to decrease with increasing measurement scale. Variance reduction arises because larger sample volumes average over more heterogeneity than do smaller volumes and hence the variance must decrease with increasing measurement scale. The behavior of the skewness on the other hand is difficult to predict given its sensitivity to both the structure and scale of the heterogeneity relative to that of the measurement. Here the skewness decreases, reflecting the exponential decrease in the pumice size frequency (Figure 2). The decreasing mean is simply a result of the decreasing sample skewness.

The semi-variograms measured on the Tiva Cliff sample are shown in Figure 4. The semi-variograms have been normalized to a variance of one to allow their plotting on a single graph. Spatial continuity was found to be relatively weak in all search directions. The semi-variograms exhibiting the strongest correlation, oriented $45^{\circ}$ from the $x$ axis, are shown. All five sample semi-variograms are characterized by a weak hole effect, indicative of a periodic structure probably related to the general spacing of the pumice in the sample. The frequency of the structure $(\sim 20 \mathrm{~cm})$ is found to be relatively consistent regardless of measurement scale.

The distribution functions measured on the Tiva Cap sample are shown in Figure 5. The behavior is qualitatively similar to that of the Tiva Cliff sample; the distributions are non-normal and the mean, variance, and skewness decrease with increasing measurement scale. However, changes in the distribution function are not as pronounced as was seen for the Tiva Cliff sample. This is believed to be the result of the overall smaller size of the pumice present in the Tiva Cap sample (Figure 2). More specifically, measurements made with a given tip seal integrate over more heterogeneity in the case of the Tiva Cap sample than the Tiva Cliff'sample thus producing a smoother change in the distribution function.

The normalized semi-variograms measured on the Tiva Cap sample are shown in Figure 6. As the measured spatial continuity was found to be isotropic the omni-directional semivariograms are given. The three smaller tip seals reveal a pure nugget effect suggesting any spatial continuity that may be present is at a scale smaller than the resolution of the instrument/sampling grid. However, the two large tip seals exhibit increasing spatial continuity. The $1.27 \mathrm{~cm}$ tip seal has a range of $10 \mathrm{~cm}$ while the $2.54 \mathrm{~cm}$ tip seal has a range of $20 \mathrm{~cm}$. The increasing range is indicative of the increasing overlap between neighboring measurements. In fact, the measured spatial continuity matches the effective radius of measurement assumed in Equation 2 (e.g., for the $1.27 \mathrm{~cm}$ tip seal, measurements must be spaced $10 \mathrm{~cm}$ apart before neighboring measurement no longer overlap). The semi-variograms associated with the two largest tip seals exhibit the same basic shape and have been fit with a spherical model.

\section{Modeling of Scaling Behavior}

In this study, the behavior of the distribution functions and variograms have been taken as measures of property scaling. These statistical descriptions of the data are of prime concern because they represent the basic input to property field simulators. Definite trends in both the distribution functions and semi-variograms have been noted for the two samples tested. At 
this point in the analysis it is necessary to quantify the measured scaling behavior.

Modeling of the scaling behavior of the distribution function can be accomplished using the simple quartile-quartile plot $(\mathrm{Q}-\mathrm{Q}$ plot). The Q-Q plot provides a convenient method for plotting one distribution function against another thus giving a qualitative measure of how the two distributions differ. For example, if the fitted curve does not extrapolate to the origin the means of the distributions are different; if the slope of the curve differs from one, the variances are different; and if the curve is not straight, the skewness of the distributions are different. Figure 7 and 8 show the Q-Q plots for the Tiva Cliff and Tiva Cap samples, respectively, where the $0.15 \mathrm{~cm}$ tip seal distribution function has been plotted relative to each of the larger tip seals. As such, these Q-Q plots show how the distribution function scales relative to the smallest tip seal. A power function has been fit to each Q-Q plot,

$$
y=c x^{d}
$$

where $c$ is the slope coefficient and $d$ is the power coefficient. It is apparent that the slope coefficient is most sensitive to changes in the variance of the distributions while the power coefficient is sensitive to changes in the skewness.

The slope and power coefficients have been plotted as a function of measurement scale (effective radius of the measurement) for both the Tiva Cliff and Tiva Cap samples (Figures 9-11). Curves have then been fit to the data forming quantitative scaling models for the distribution functions of the two samples. It is interesting to note that in both cases the slope coefficient scales exponentially while the power coefficient scales in a linear manner. Although the scaling behavior of the two samples can be modeled with the same functional relations, the degree to which the they scale is very different. This behavior is again attributed to the overall smaller size of the heterogeneity in the Tiva Cap sample. One should note that there is a scale of heterogeneity finer than the resolution of the permeameter (the pore scale), and hence the empirical scaling models should not be extrapolated to scales smaller than that measured with the 0.15 cm tip seal. Efforts are currently being made to calculate analogous models where the scaling behavior can be described by simple volume averaging (as is the case for porosity, ore grade, etc.) to provide a point of reference for the empirical scaling models presented here.

Scaling of the semi-variogram is also of interest. Theory suggests that the basic shape of the semi-variogram should remain the same with increasing scale while the sill, if one exists, will decrease. ${ }^{10,27}$ For both samples, this was found to be the case. The range of the semi-variogram, again if one exists, should increase but only in proportion to the increasing measurement scale. Results for the Tiva Cap sample support this statement; however, the range or frequency of the Tiva Cliff sample did not change. In the case of the Tiva Cliff sample changes in the range are believed to be masked by the periodicity of the heterogeneity which is at a similar frequency to that of the sampling grid and measurement scales employed.

\section{Conclusions}

Because many constitutive rock properties must be measured at one scale but applied at another, scaling behavior is an issue facing many applied disciplines, including the petroleum industry. A research program has been established to investigate and quantify scaling behavior through systematic physical experimentation. The results of experiments conducted on two blocks of volcanic tuff are given. The measured scaling behavior was noted to be very different for the two samples, owing to differences in the heterogeneity structure of the rock samples. The measured scaling behavior is characterized by variations in predominately non-Gaussian distribution functions and the semivariograms. Simple models have been fit to the measured scaling behavior, which are of similar functional form but of very different magnitude. It should be noted that even for the relatively narrow range of measurement scales employed, which are on the order of the common core sample, significant changes in the distribution functions and variograms occurred. Because such data descriptors represent the basic input for effective media property simulators, these results demonstrate both the need to understand and accurately model scaling behavior.

Although the rock samples used in the tests presented here do not represent important reservoir materials, results gained from these tests provide important insight into scaling behavior. Never-theless, plans are currently being made to collect sandstones, shales, limestones, and fractured reservoir materials for investigation. As experience is gained through such investigations efforts will be made to develop empirical scaling laws which will be used to test and refine current theory pertaining to the scaling of constitutive properties.

\section{Acknowledgments}

I would like to acknowledge Justin VonDoemming and Kerim Martinez for their help in constructing the permeameter and their help in data collection. I would like to thank Bob Glass, John Wilson (NM Tech), and Alan Gutjhar (NM Tech) for their valuable comments and advice concerning this work This work was supported by the U.S. Department of Energy, Office of Civilian Radioactive Waste Management, Yucca Mountain Site Characterization Project Office, under contract DEAC04-94AL85000.

\section{References}

1. G. Dagan, "Statistical Theory of Groundwater Flow and Transport : Pore to Laboratory, Laboratory to Formation, and Formation to Regional Scale," Water Resources Research, Vol.22, pp. 120S-134S (1986).

2. H. H. Haldorson, "Simulator Parameter Assignment and the Problem of Scale in Reservoir Engineering," in Reservoir Characterization (L.W. Lake and H.B. Carroll, Jr., ed.), pp. 293340 (1986). 
3. E.H. Isaaks, and R.M. Srivastava, An Introduction to Applied Geostatistics, Oxford University Press, New York (1989).

4. S. P. Neuman, "Universal Scaling of Hydraulic Conductivities and Dispersivities in Geologic Media," Water Resources Research, Vol.26, pp. 1749-1758 (1990).

5. J.H. Cushman, ed., Dynamics of Fluids in Hierarchical Porous Media, Academic Press, New York, (1990).

6. J.H. Cushman, "On Measurement, Scale, and Scaling," Water Resources Research, Vol.22, pp. 129-134 (1986).

7. L.W. Gelhar, Stochastic Subsurface Hydrology, Prentice Hall, Englewood Cliffs, New Jersery, pp. 390 (1993).

8. J.L. Jensen, "Use of the Geometric Average for Effective Permeability Estimation," Mathematical Geology ,Vol.23, pp. 833-840 (1991).

9. T.J. Lasseter, J.R. Waggoner, and L.W. Lake, "Reservoir Heterogeneities and their Influence on Ultimate Recovery, "in Reservoir Characterization (L.W. Lake and H.B. Carroll, Jr., ed.), pp. 545-560 (1986).

10. H. Parker, "The Volume Variance Relationship: A Useful Tool for Mine Planning," in Geostatistics, (Mousset-Jones, P., ed.) pp. 61-91, McGraw Hill, New York (1980).

11. C.A. Rautman, and T.H. Robey, "Recent Developments in Stochastic Modeling and Upscaling of Hydrologic Properties in Tuff," in Proceedings of the Fourth High-Level Radioactive Waste Management Conference, April 26-30, 1993, Las Vegas, Nevada, pp. 1437-1445 (1993).

12. S.W. Wheatcraft, and S.W. Tyler, "An Explanation of Scale-Dependent Dispersivity in Heterogeneous Aquifers Using Concepts of Fractal Geometry," Water Resources Research. Vol.24, pp. 566-578 (1988)

13. F.J. Moltz, O. Guven, J.G. Melville and C. Cardone, "Hydraulic Conductivity Measurement at Different Scales and Contaminant Transport Modeling, "Chapter III, in Dynamics of Fuids in Hierarchical Porous Media, (J.H. Cushman, ed.), Academic Press, New York, pp. 37-59 (1990).

14. J.C. Parker and K.A. Albrecht, "Sample Volume Effects on Solute Transport Predictions," Water Resources Research, Vol.23, pp. 2293-2301 (1987).

15. J.B. Sisson and P.J. Wierenga, "Spatial Variability of Steady-State Infiltration Rates as Stochastic Processes, "Soil Science Society of America Journal, Vol.45, pp. 699-704 (1981).

16. V.C. Tidwell, J.D. VonDoemming, and K. Martinez, "Scale Dependence of Effective Media Properties, "in Proceedings of the
Fourth High-Level Radioactive Waste Management Conference, April 26-30, 1993, Las Vegas, Nevada, pp. 1059-1065 (1993).

17. M.A. Chandler, G. Kocurek, D.J. Goggin, and L.W. Lake, "Effects of Stratigraphic Heterogeneity on Permeability in Eolian Sandstone Sequence, Page Sandstone, Northern Arizona," American Association of Petroleum Geologists Bulletin, Vol.73, pp. 658-668 (1989).

18. J.M. Davis, R.C. Lohmann, F.M. Phillips, J.L. Wilson, and D.W. Love, "Architecture of the Sierra Ladrones Formation, Central New Mexico: Depositional Controls on the Permeability Correlation Structure," Geological Society of America Bulletin, Vol.105, pp. 998-1007 (1993).

19. C.M. Fuller and J.M. Sharp, Jr., "Permeability and Fracture Patterns in Extensive Volcanic Rocks: Implication from the Welded Santana Tuff, Trans-Pecos Texas," Geological Society of America Bulletin, Vol.104, pp. 1485-1496 (1992).

20. M.G. Kittridge, L.W. Lake, F.J. Lucia, and G.E. Fogg, "Outcrop/Subsurface Comparisons of Heterogeneity in the San Andres Formation, "SPE Formation Evaluation, pp. 233-240 (1990)

21. J.M. Sharp, Jr., L. Fu, P. Cortez, E. Wheeler, "An Electronic Minipermeameter for Use in the Field and Laboratory," Ground Water, in press.

22. J.M. Davis, J.L. Wilşon, and F.M. Phillips, "A Portable Air-Minipermeameter for Rapid In-Situ Field Measurements," Ground Water, in press.

23. S.C. Jones, "A Rapid Accurate Unsteady-State Klinkenberg Permeameter," Society of Petroleum Engineers Joumal, SPE3535, pp. 385-397 (1972).

24. V.C. Tidwell, "Scaling Behavior of Gas Permeability Measurements in Volcanic Tuffs," in Proceedings of the Fifth High-Level Radioactive Waste Management Conference, May 22-26, 1994, Las Vegas, Nevada, pp. 2500-2509 (1994).

25. D. J. Goggin, R. L. Thrasher, and L. W. Lake, "A Theoretical and Experimental Analysis of Minipermeameter Response Including Gas Slippage and High Velocity Flow Effects," In Situ, Vol. 12, 79-116 (1988).

26. R.T. Scott and J. Bonk, "Preliminary Geologic Map of Yucca Mountain, Nye County, Nevada, with Geologic Sections," U.S. Geological Survey Open-File Report 84494 (1984).

27. I. Clark, "Regularization of a Semivariogram," Computers andGeosciences, Vol. 3, pp. 341-346 (1977). 


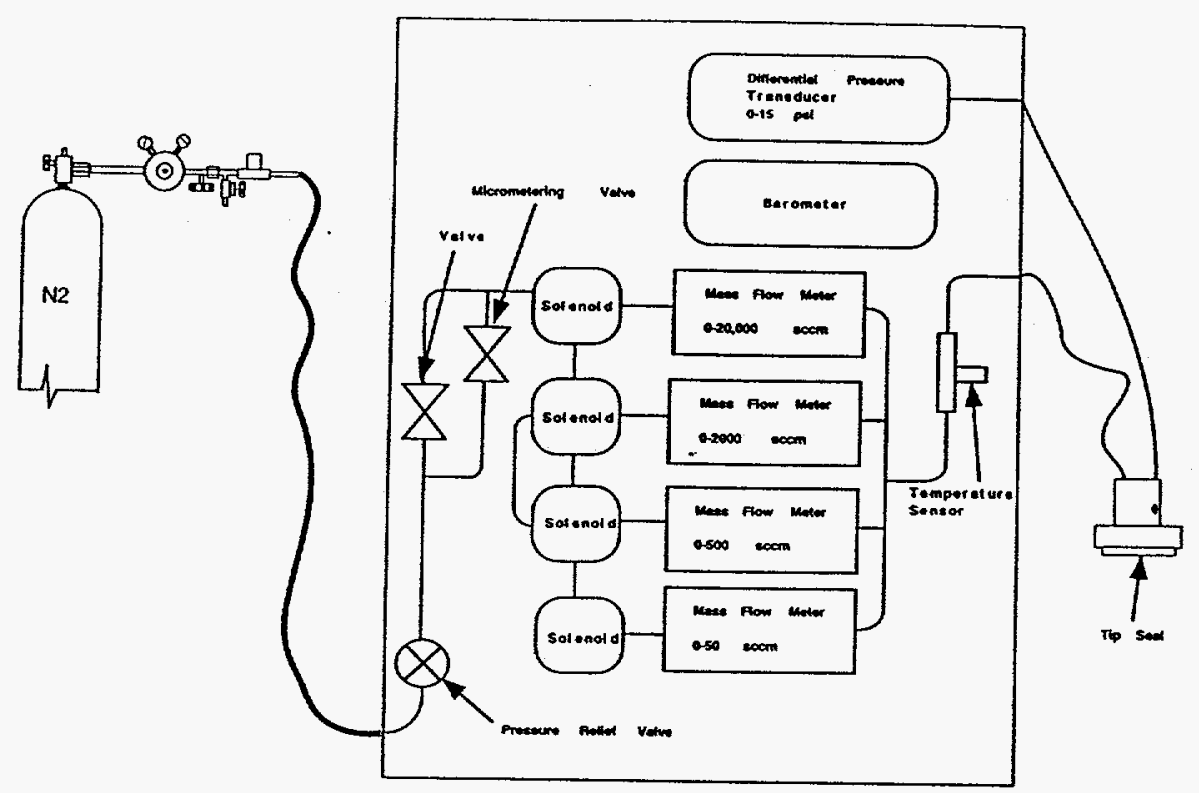

a).

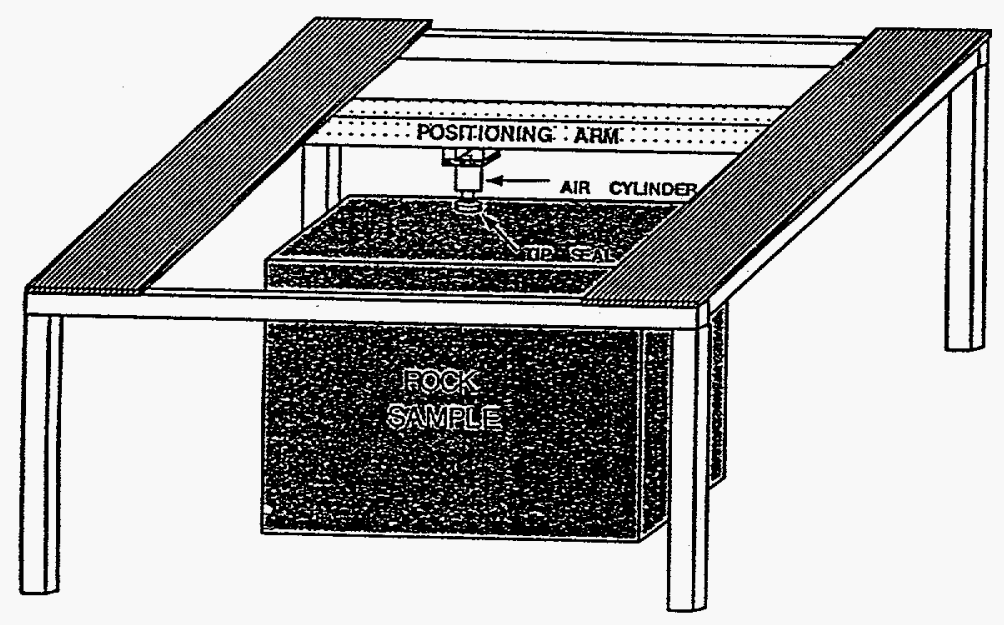

b).

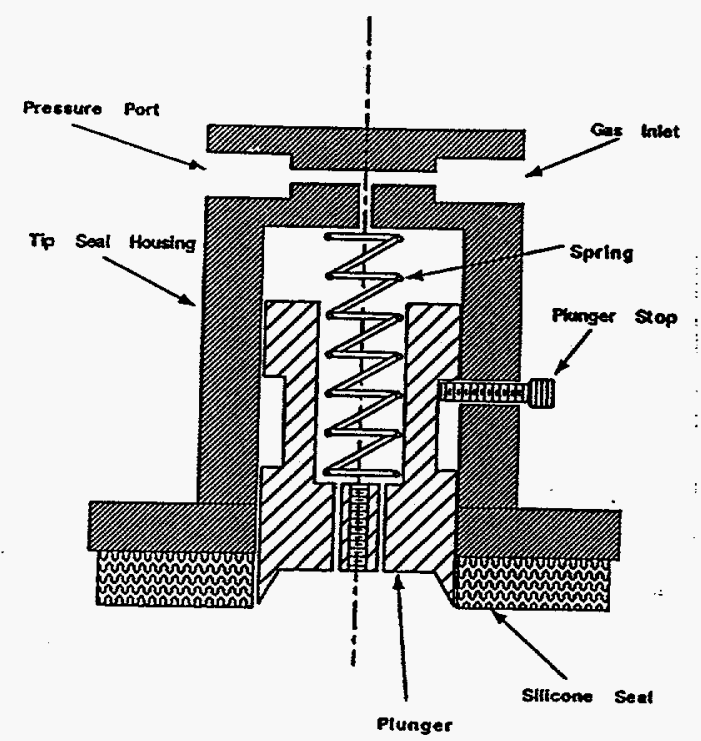

c). Figure 1. Automated gas-permeameter test system; a) schematic of electronic gas permeameter, b) schematic of positioning system,
c) schematic of tip seal. 


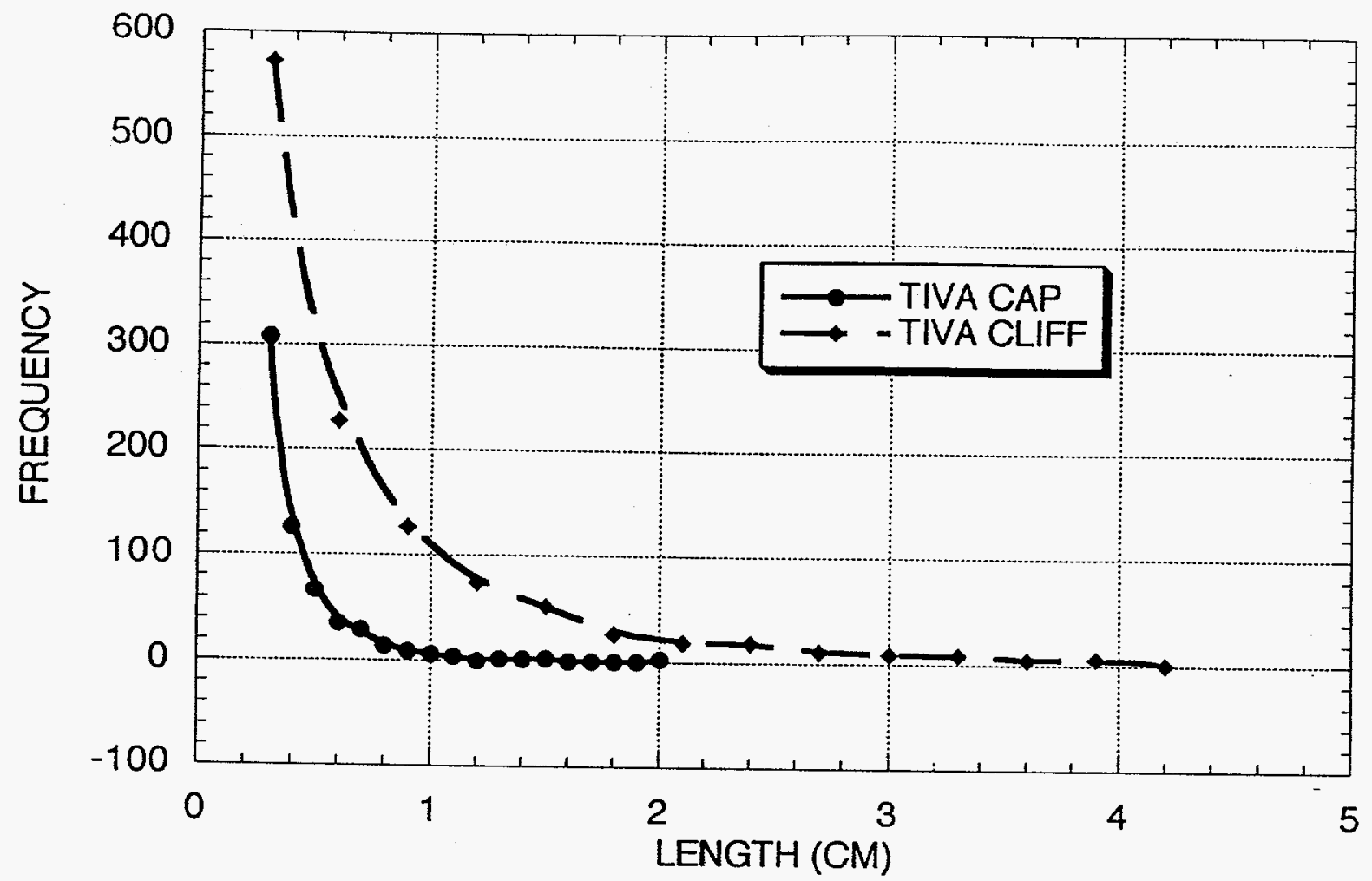

Figure 2. Frequency distribution of pumice grain size (length of major axis) for the two rock samples tested. Measurements were acquired using high resolution optical imaging techniques.

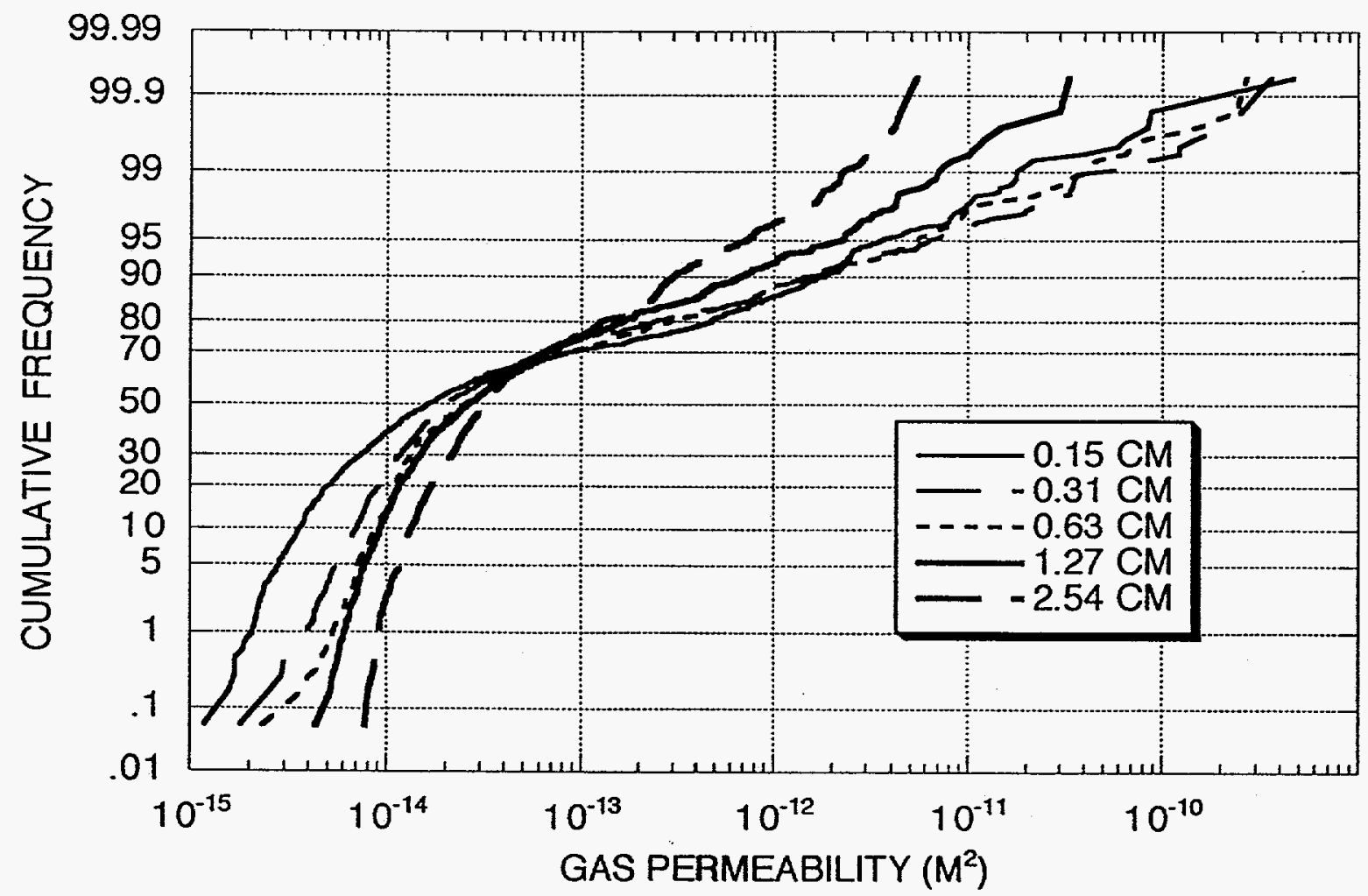

Figure 3. Comparison of distribution functions measured with different size tip seals on the Tiva Ciff sample. 


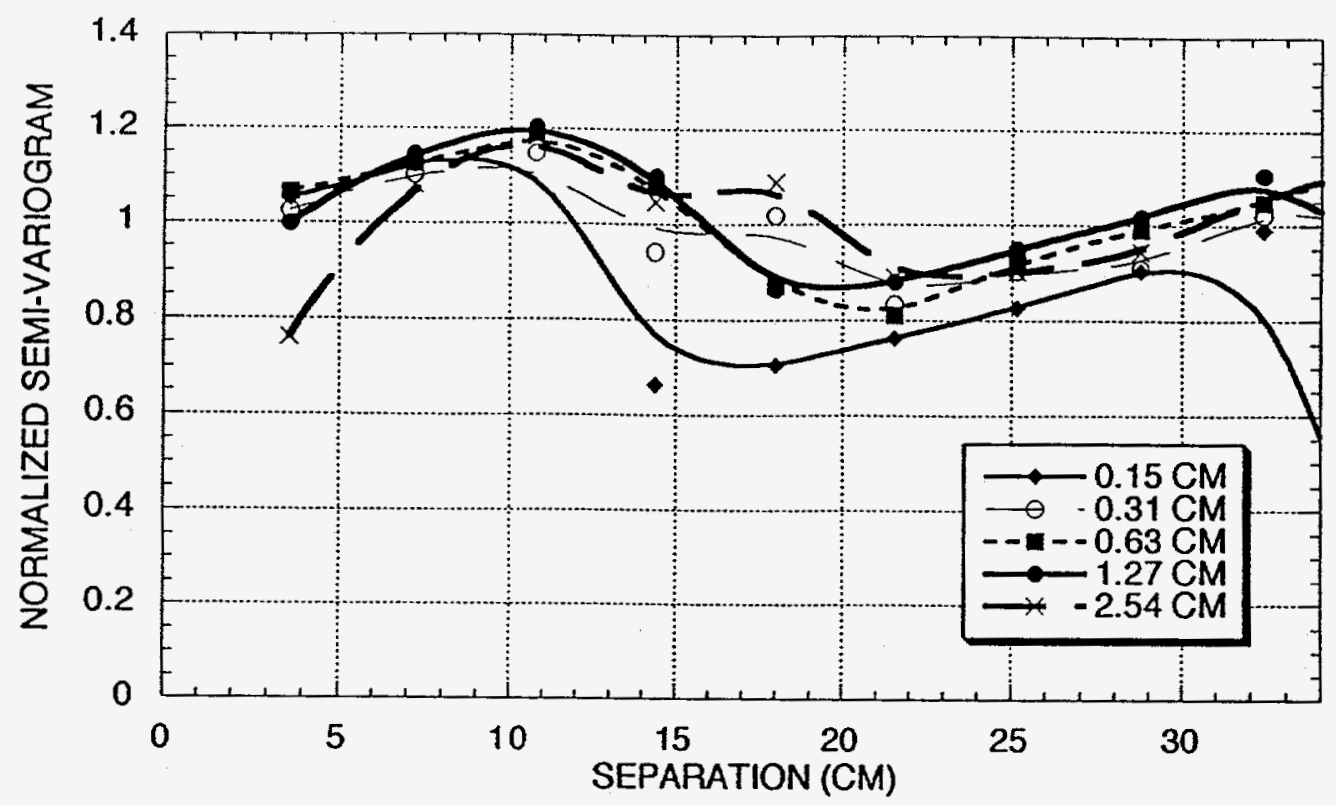

Figure 4. Comparison of sample semi-variograms measured with different size tip seals on the Tiva Cliff sample. Semi-variograms are provided for a search direction oriented $45^{\circ}$ to the $x$-axis. Smoothed curves have been fit to the data to help distinguish individual semi-variograms.

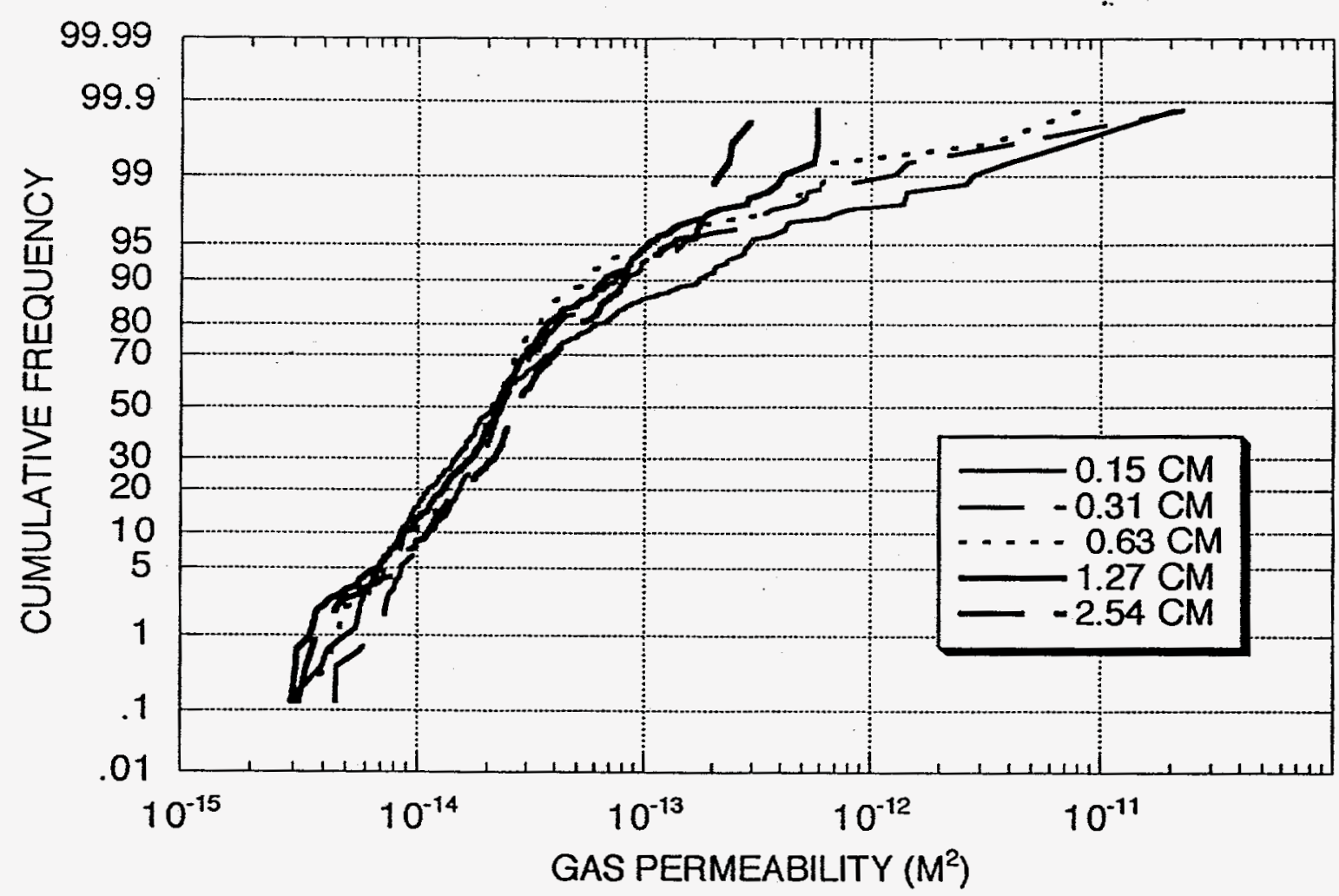

Figure 5. Comparison of distribution functions measured with different size tip seals on the Tiva Cap sample. 


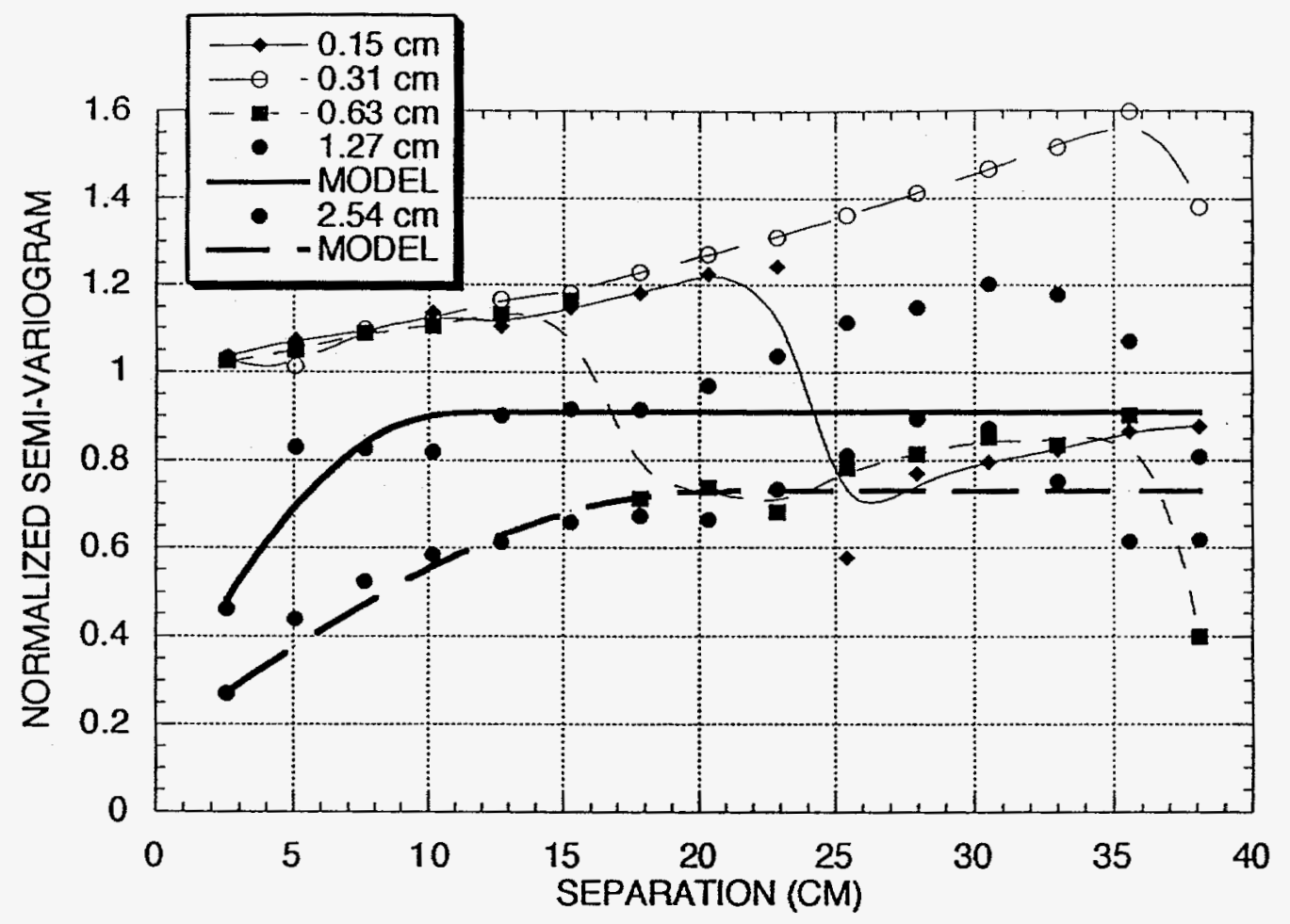

Figure 6. Comparison of sample semi-variograms measured with different size tip seals on the Tiva Cap sample. The omnidirectional semi-variograms are provided. Smoothed curves are fit to the $0.15,0.31$, and $0.63 \mathrm{~cm}$ tip seal data while a spherical model has been fit to the 1.27 and $2.54 \mathrm{~cm}$ tip seal data.

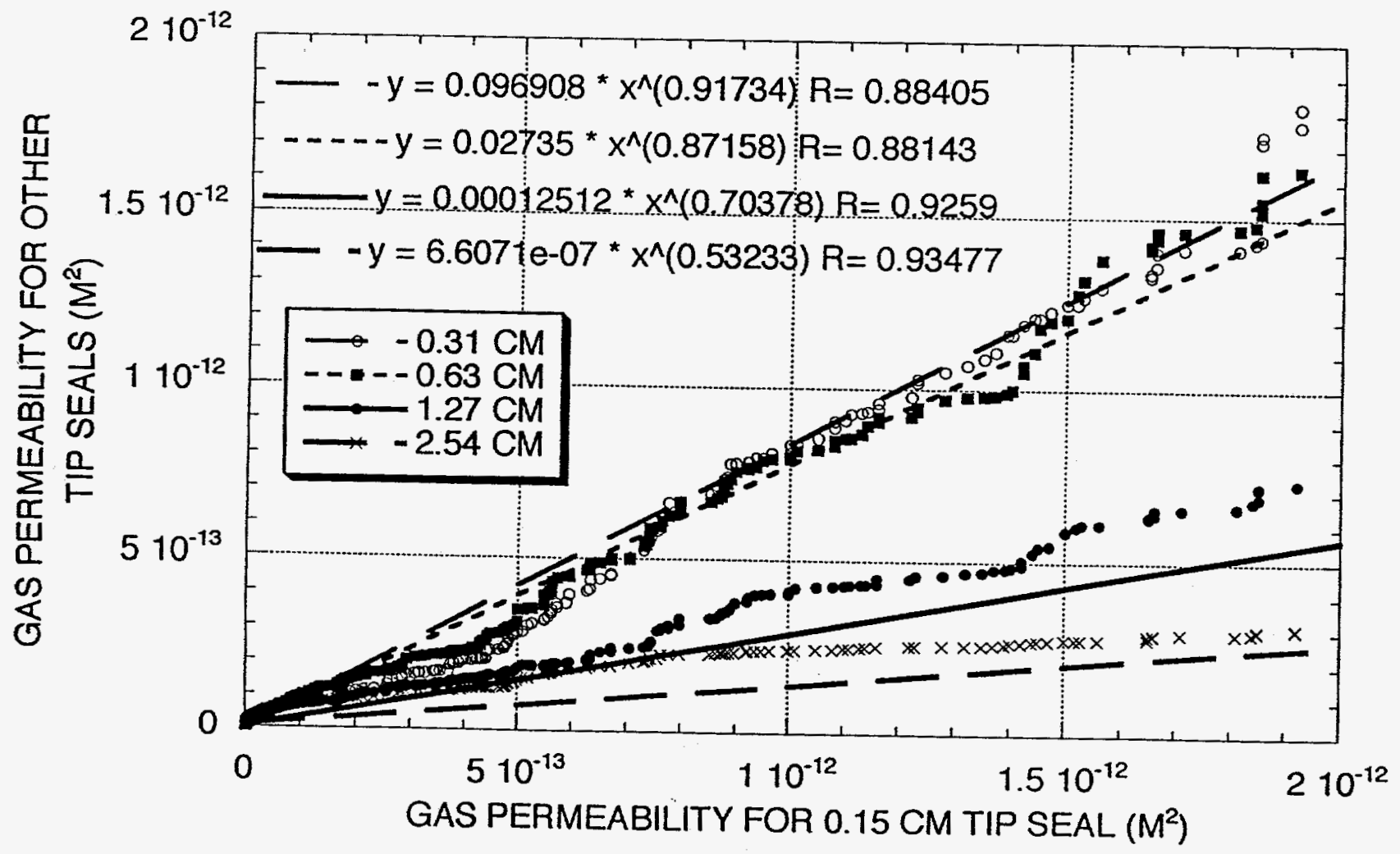

Figure 7. Q-Q plot for the Tiva Cliff sample and fitted power functions. 


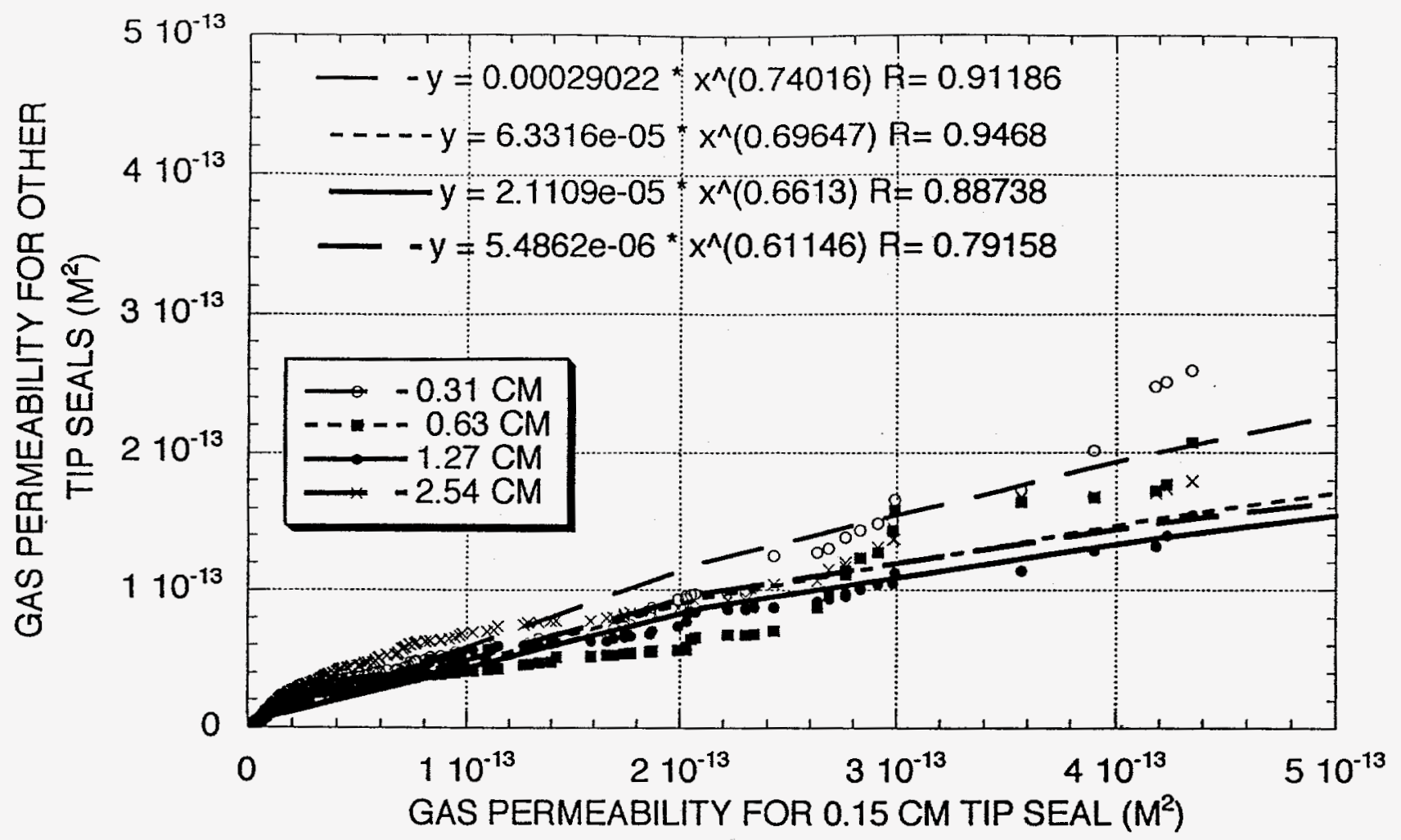

Figure 8. Q-Q plot for the Tiva Cap sample and fitted power functions.

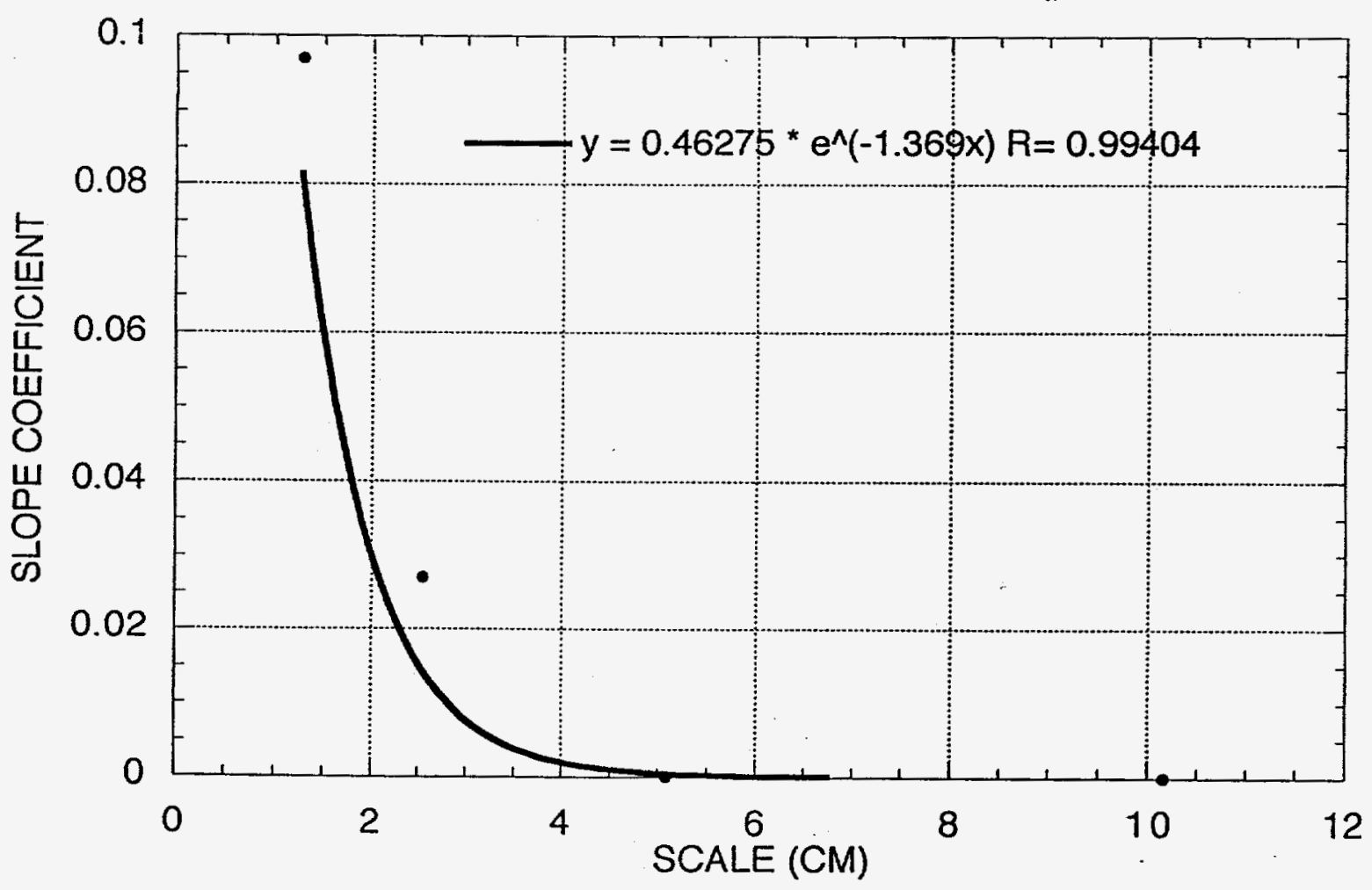

Figure 9. Scaling of the slope coefficient for the Tiva Cliff sample. 


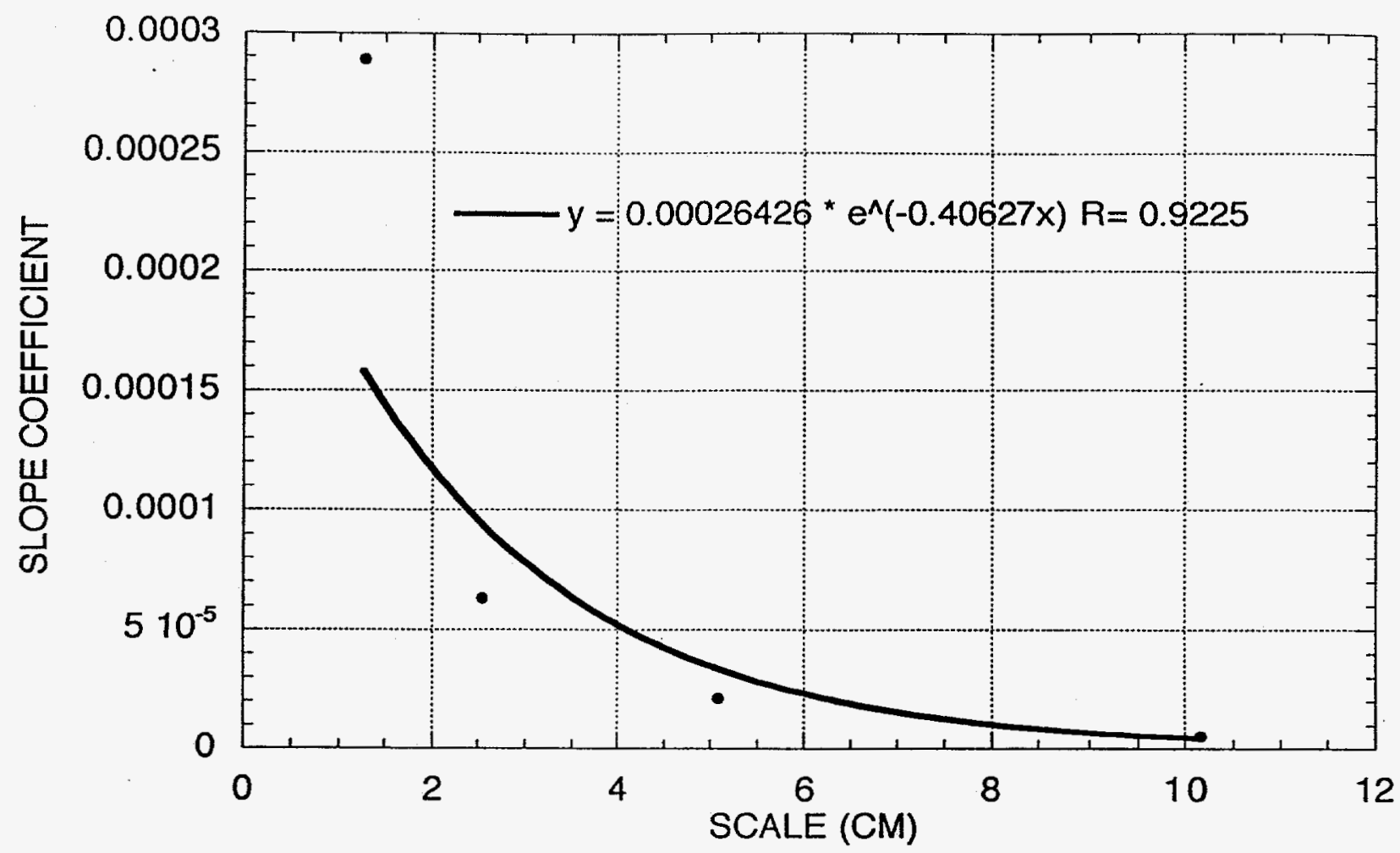

Figure 10. Scaling of the slope coefficient for the Tiva Cap sample.

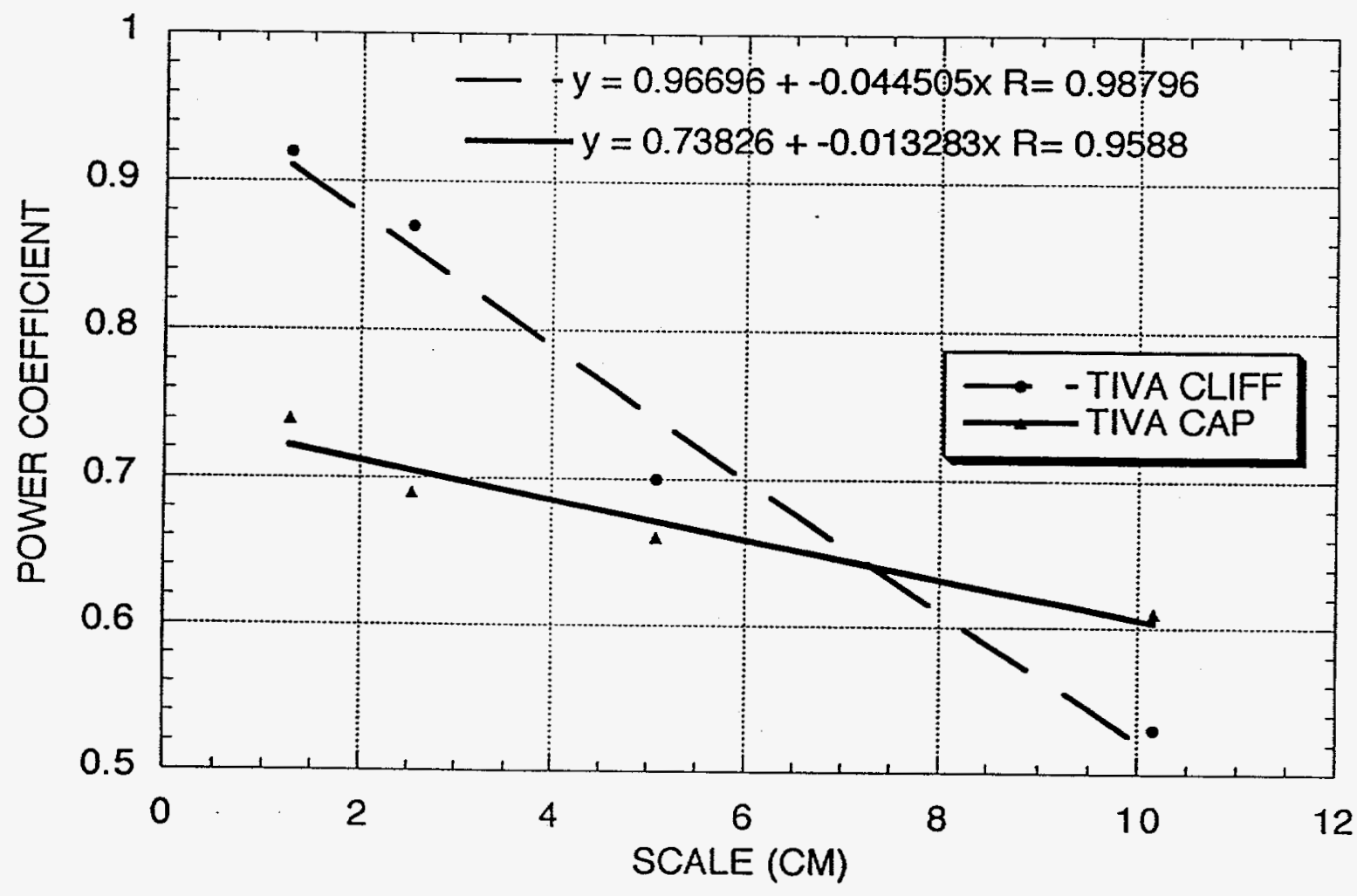

Figure 11. Comparison of the scaling behavior of the power coefficient for the Tiva Cliff and Tiva Cap samples. 